\section{Comparison of two balance training programs on balance in community dwelling older adults}

\author{
Shefali Walia, ${ }^{1}$ Majumi M. Noohu² \\ 'ISIC Institute of Rehabilitation Sciences, \\ New Delhi; ${ }^{2}$ Centre for Physiotherapy and \\ Rehabilitation Sciences, Jamia Millia \\ Islamia, New Delhi, India
}

\section{Abstract}

Impaired balance has been associated with an increased risk for falls and a resulting increase in the mortality rate of elder people. Thus, balance-training interventions have an important place in fall prevention. This study was designed with the purpose of identifying the appropriate balance-training program for community dwelling elderly adults with an active lifestyle. A sample of 70 elderly adults were randomly allocated into two groups: group $1(n=35)$ received general balance and mobility exercise; group $2(n=35)$ received specific balance strategy training. The intervention consisted of 5 sessions/week for 4 weeks. The outcome measures were Timed up and go test (TUGT) and Berg balance scale (BBS). An inter-group (2-way mixed model analysis of co-variance) and intra-group (repeated measures) analysis was done to find the change in balance scores. After the intervention, the TUGT scores in group 1 were, mean $=10.38 \mathrm{~s}$, standard deviation $(\mathrm{SD})=1.59 \mathrm{~s}$ and in group 2 were, mean $=9.27 \mathrm{~s}, \mathrm{SD}=1.13 \mathrm{~s}$. Post training, BBS scores for group 1 were, mean $=54.69, \mathrm{SD}=1.13$, and for group 2 were, mean $=55.57, \mathrm{SD}=0.56$. There was a significant group $\times$ time effect for TUGT and BBS score. All the subjects showed significant changes in balance scores after balance training interventions. The subjects who participated in the specific balance-strategy training significantly improved their functional mobility, as shown on the TUGT, compared to the general training group.

\section{Introduction}

About $10 \%-25 \%$ of falls in older adults are associated with poor balance and gait abnormalities. ${ }^{1}$ Literature on geriatric balance training is a medley of non-specific interventions characterized by conventional callisthenic (coordination) exercises, which often include aerobic or muscle-strengthening components. ${ }^{2}$ Several investigators have examined the effect of a single form of exercise on balance in older adults, with mixed results. ${ }^{3-6}$ Balance training has shown to improve the different aspects of postural control. ${ }^{7}$ Individualized balance training has shown improvement in balance scores such as BBS and dynamic gait index and a 9week balance training by Ledin et al., also led to changes in balance performance. ${ }^{8,9} \mathrm{Nitz}$ and Choy, in their study determined the effectiveness of specific balance strategy training program in contrast to control group for preventing falls among older people. They believed that no previous study had investigated the efficacy of a specific balance strategy-training program presented through a workstation or circuit program as the exercise intervention. ${ }^{10}$ Means et al., identified the effectiveness of the general balance and mobility exercise program for improving balance in elderly population. ${ }^{11}$

The meta analysis of Frailty and injuries: cooperative studies of intervention techniques (FICSIT) trails, recommends balance training as one of the better options for fall prevention in older adults. ${ }^{12}$ Province et al. used a metaanalysis to examine the effects of exercise on falls and fall-related injuries among seven different facilities participating in the FICSIT study and it was found that exercise reduced the risk of falls. The largest effect was in those trials that involved balance training (17\% relative risk reduction), rather than strength or endurance training. Province et al. thus, concluded that some form of balance retraining appears to be the most effective type of exercise for reducing fall risk. ${ }^{13}$

It becomes difficult to determine which type of balance training is the most effective from the existing evidence and the view is supported by Howe et al. ${ }^{14}$ This study aims to compare the effect of specific balance-strategy training and general balance and mobility exercise program on the improvement in balance scores in the community dwelling elders. The two interventions used in the study were: general balance and mobility exercise program and specific balance strategy training program. Though the first intervention program focuses on flexibility, strengthening and postural exercises, the second intervention focuses on practicing specific functional tasks in a workstation format such as sit-to-stand, stepping up and down, sideways reaching and ball games.

\section{Materials and Methods}

\section{Participants}

The subjects were recruited through a geriatric camp organized at Indian Spinal Injuries Center, Vasant Kunj, New Delhi. Residents of Vasant Kunj volunteered for the study. Inclusion criteria required the participants to
Correspondence: Majumi M. Noohu, Centre for Physiotherapy and Rehabilitation Sciences, Jamia Millia Islamia, New Delhi-111025, India. Tel.: +91.9868023378 - Fax: +91.(11).2698.0229.

E-mail: mnoohu@jmi.ac.in

Key words: Balance; injury; function; falls.

Contributions: SW, MMN, research concept, data analysis and interpretation, manuscript writing and references search; SW, data collection.

Conflict of interest: the authors declare no potential conflict of interest.

Received for publication: 12 June 2016. Revision received: 10 August 2016.

Accepted for publication: 11 August 2016.

This work is licensed under a Creative Commons Attribution-NonCommercial 4.0 International License (CC BY-NC 4.0).

(C) Copyright S. Walia and M.M. Noohu, 2016 Licensee PAGEPress, Italy

Geriatric Care 2016; 2:6081

doi:10.4081/gc.2016.6081

be independent community dwellers above the age of 65 years with mini-mental status examination (MMSE) scores above 24, without history of a fall within one year. Ninety subjects fulfilled the inclusion criteria out of 70 agreed to attend the exercise program regularly, took part in this study. These subjects were then randomly allocated into two groups, which received different balance training interventions. Lottery method was used for allocation in which the numbers were written and enclosed in a sealed envelope. It was picked randomly without replacement. Group 1 consisting of 35 subjects received general balance and mobility exercise while group 2 also consisting of 35 subjects received specific balance-strategy training. The age (years), height $(\mathrm{kg})$, weight $(\mathrm{cm})$, MMSE, number of medications used were collected from all the subjects. Small groups of up to 6-7 participants were formed who together performed all exercises. The exercises were done under the supervision of two physiotherapists specially dealing with balance and postural control training with two attendants to prevent falls and injuries to the participants. The subjects were neither institutionalized/hospitalized nor dependent on activities of daily living. Subjects were excluded if they had an acute illness that may interfere in the participation for the study, an unstable cardiac condition, any orthopedic or neurological illness, permanent history of dizziness, severe or uncorrected visual deficit and use of sedative drugs also made the subjects ineligible for participation. The study has been approved by the research review commit- 
tee, Indian Spinal Injuries Centre, New Delhi that looked into and cleared the ethical aspects of the study.

\section{Intervention}

Subjects of group 1 received the general balance and mobility exercise program which consists of active stretching and strengthening of the lower limb muscles, postural control exercises, endurance walking and repetitive muscle coordination exercises. This program initially started with a low level of intensity (low frequency and repetitions) of individual exercises and was progressive over the weeks. The resistance applied and rest period was adjusted individually so that participants could exercise at a subjectively moderate intensity. ${ }^{11}$

Subjects of group 2 received a specific balance-strategy training program A workstation was designed to focus on a specific task that addresses various aspects required for balance including functional strength, flexibility, balance strategy practice, sensory integration, and added attentional demands during function and multi-task practice. Various simple tasks were selected such as sit to stand. This task was practiced using different chair heights, with/without upper limb assistance, balancing a cup with/without water on a saucer or while adding a cognitive task to the manual task. Each task was graded to cater to

Table 1. Details of exercises for group 1 and 2.

Group 1
Flexibility exercises
Hamstring stretch
Gluteus maximus and hip flexor stretch
Gastrocnemius and soleus stretch
Strengthening exercises - lower limb muscles
Quadriceps (sitting and straight leg raises)
Hamstrings
Gluteus maximus
Gluteus medius
Postural exercises
Head and neck
Trunk
Coordination exercises
Reciprocal leg movements
Bridging
Sitting/standing
Group 2

\section{Sit to stand to sit}

Stepping in all directions (forwards, side and back)

Reaching to limits of stability

Step up and down

Ankle, hip and upper limb balance strategy practice Sideways reach task

Ball games various levels of ability so that participants can have the level of difficulty progressed to increase the challenge. This versatility of degree of difficulty also allows for accommodation to various levels of ability of individual participants. Workstation application encourages self-efficacy in the participants allowing them to increase the challenge at each station. Also, training programs designed in a workstation format allow easy duplication in the home environment. ${ }^{10}$

All subjects attended the exercise program 5 times a week for 4 weeks, each station lasting for 30 min each. The exercise of group 1 and 2 is given in Table 1. All of them used to come from their homes daily either walking or by their own car. All subjects were ambulatory and used to carry out their basic and instrumental activities of daily living themselves.

\section{Outcome measures}

The subjects were assessed on the two balance scales, the Timed up and go test ${ }^{15}$ (TUGT) and the Berg balance scale (BBS) ${ }^{16}$ before the exercises and after 4 weeks of training. In TUGT the subject was made to sit in a chair of standard height and asked to walk a distance of $3 \mathrm{~m}$ and turn around and sit back in the chair. The total time taken (in seconds) for the activity was recorded as TUGT score. BBS consists of 14 activities which was scored on a 5 point ordinal scale with maximum score 56 and minimum score of 0 . Elements of the test are supposed to be representative of daily activities that require balance. They include simple mobility tasks (e.g., Transfers, standing unsupported, sit to stand) and more difficult task (e.g., Tandem standing, turning 360 degree, simple leg stance). Both the balance tests were found to be reliable and valid tools for measuring balance in community dwelling older adults. ${ }^{15,17-19}$

\section{Data analysis}

Statistical analysis was performed using SPSS 19 statistics software (IBM Corp., Armonk, NY, USA). Two way-mixed model analysis of co-variance was used to analyze the difference between group 1 and group 2, with pre-intervention score as a covariate and group as a factor to find out the main effect and group $\times$ time effect. A within group analysis between pre-intervention and post-intervention scores using repeated measures analysis was done. Unpaired t-test was used to analyze the difference between pre intervention scores of TUGT and BBS scores, age, height and weight between the groups. Pearson's chisquare test was used to find out any significant difference in number of medicines used by the participants in two groups. A significance level of $\mathrm{P} \leq 0.05$ was fixed. A post hoc power analysis was done using software $\mathrm{G}^{*}$ power $3 .^{20}$

\section{Results}

There was no significant difference for demographic characteristics between the groups. The mean \pm standard deviation (SD) of age, height, weight, MMSE score of participants of both groups are given in Table 2. In group $1 ; 15,14,5$, number of participants were using 1,2 and 3 number of medicines while in group $2 ; 18,11,4$, number of participants were using 1, 2 and 3 number of medicines respectively. Total of 3 participants were not using any medicine (1 participant in group 1 and 2 participant in group 2). Pearson chi-square test results showed there was no significant difference between the groups in terms of usage in number of medicines $(\mathrm{P}=0.78)$. The mean \pm SD of pre-intervention and post intervention TUGT and BBS scores for group 1 and group 2 are given in Table 3 .

In a between group comparison there was a significant group $\times$ time effect for TUGT score $(\mathrm{P}=0.001)$ and power $=0.80$ with a moderate effect size (partial Eta-squared=0.56) as well as a significant group $\times$ time effect for BBS score $(\mathrm{P}=0.001)$ with moderate effect size (partial Eta-squared=0.57) and power=0.81 (Table 4). The TUGT scores did not show any significant difference between the groups for main effects $(\mathrm{P}=0.47)$, while BBS scores showed a signifi-

Table 2. Demographic data: comparison between group 1 and 2 using unpaired t-test.

\begin{tabular}{|c|c|c|c|c|}
\hline Background information & $\begin{array}{c}\text { Group } 1 \\
\text { N=35 } \\
\text { Males }=17 \\
\text { Females }=18 \\
\text { (mean } \pm \text { SD) }\end{array}$ & $\begin{array}{c}\text { Group } 2 \\
\text { N=35 } \\
\text { Males }=20 \\
\text { Females }=15 \\
(\text { mean } \pm \text { SD) }\end{array}$ & $\mathrm{t}$ & $P$ \\
\hline Age, year & $69.34 \pm 4.30$ & $69.89 \pm 4.23$ & -0.53 & 0.60 \\
\hline Height, cm & $159.73 \pm 9.33$ & $159.49 \pm 7.60$ & 0.11 & 0.91 \\
\hline Weight, kg & $66.69 \pm 6.99$ & $66.29 \pm 8.40$ & 0.21 & 0.83 \\
\hline MMSE & $26.29 \pm 1.07$ & $26.49 \pm 1.12$ & -0.76 & 0.44 \\
\hline
\end{tabular}

Group 1, general balance and mobility exercise group; group 2, specific balance strategy training program group. SD, standard deviation; MMSE, mini-mental state examination. 
cant difference between the groups for main effects $(P=0.001)$ and the effect size for main effects on BBS score is low (partial Etasquared=0.19). Repeated measures analysis showed significant difference in the pre-intervention and post-intervention TUGT with a high effect size (partial Eta-squared value) in both groups. BBS scores pre-intervention and postintervention also showed significant difference for both groups with a high effect size (partial Eta-squared value) (Table 5).

\section{Discussion}

The findings of the study suggest that the groups did not differ on TUGT scores $(t=-$ $0.011, \mathrm{P}=0.90)$ and BBS $(\mathrm{t}=-0.055, \mathrm{P}=0.58)$ before the intervention. While the changes that was taking place in TUGT scores and BBS score between groups were significantly different over the time with different exercises (group $\times$ time effect).

Participants receiving the specific balance- strategy training program performed better on both the balance scales in comparison to participants receiving the general balance and mobility training. Improved scores in the group 2 participants could be as a result of the composition of tasks they practiced. These tasks contained elements that encouraged participants to bend, turn and reach to limits of stability (e.g., while playing a game of ball catching and throwing) on various surfaces thereby providing added vestibular stimulation. Vestibular stimulation occurs through various functional tasks such as reaching to limits of stability, sideways reaching tasks, and ball games. This vestibular stimulation is not focused on in the general balance-training program. Though, it may not be the sole cause of difference in performance of both groups, it does have a beneficial effect when we talk about balance training. Each workstation was designed to focus on a specific task that address different aspects required for balance including functional strength, flexibility, balance strategy practice, sensory integration, and added attention demands during function and multi-task practice. Such interventions encouraged speed and size of movements, which may have increased strength and endurance in addition to improving flexibility and reaction time for the specific balancetraining group. Each station task was graded to cater to various levels of ability so that participants could have the level of difficulty progressed to increase the challenge. This versatility of degree of difficulty also allows for accommodation to various levels of ability of individual participants. This could have resulted in improved functional ability to balance, able to ambulate in the environment at a faster velocity. Support for this view comes from the improved outcomes from a similar multidimensional balance training program delivered as an individual intervention rather than small groups..$^{21}$ Participants in specific balance-strategy program practiced ball games with varying size and weight. This might have increased manual reaction speed as noted by Botello et al. ${ }^{22}$ Improved hand eye coordination also helps in maintaining visual acuity during activities of daily living. Visual feed-

Table 3. Descriptive statistics for timed up and go test and Berg balance scale pre- and post-intervention scores between groups 1 and 2.

\begin{tabular}{|c|c|c|c|}
\hline Balance scale & & $\begin{array}{c}\text { Group } 1 \\
\mathrm{~N}=35 \\
(\mathrm{mean} \pm \mathrm{SD})\end{array}$ & $\begin{array}{c}\text { Group } 2 \\
\mathrm{~N}=35 \\
\text { (mean } \pm \mathrm{SD} \text { ) }\end{array}$ \\
\hline TUGT & $\begin{array}{l}\text { Pre-intervention score } \\
\text { Post-intervention score }\end{array}$ & $\begin{array}{l}13.45 \pm 2.04 \\
10.38 \pm 1.59\end{array}$ & $\begin{array}{l}13.51 \pm 2.09 \\
9.27 \pm 1.13\end{array}$ \\
\hline BBS & $\begin{array}{l}\text { Pre-intervention score } \\
\text { Post-intervention score }\end{array}$ & $\begin{array}{l}49.74 \pm 3.78 \\
54.69 \pm 1.13\end{array}$ & $\begin{array}{c}50.17 \pm 2.62 \\
55.57 \pm 0.56\end{array}$ \\
\hline
\end{tabular}

Group 1, general balance and mobility exercise group; group 2, specific balance strategy training program group. TUGT, timed up and go test; BBS, Berg balance scale.

Table 4. Comparison between groups on timed up and go test and Berg balance scale scores using the analysis of co-variance.

\begin{tabular}{lcccc} 
Variable & Comparison between groups & F & P & $\begin{array}{c}\text { Partial Eta-squared } \\
\text { (effect sive) }\end{array}$ \\
TUGT & Group 1 $\times$ group 2 (main effect) & 0.52 & 0.47 & 0.01 \\
& Group $\times$ time (interaction) & 41.12 & $0.001^{*}$ & 0.56 \\
BBS & Group 1 $\times$ group 2 (main effect) & 16.00 & $0.001^{*}$ & 0.195 \\
& Group $\times$ time (interaction) & 44.66 & $0.001^{*}$ & 0.575 \\
\hline
\end{tabular}

Group 1, general balance and mobility exercise group; group 2, specific balance strategy training program group. TUGT, timed up and go test; BBS, Berg balance scale. *Significant at 0.05 level.

Table 5. Comparison of timed up and go test and Berg balance scale pre- and post-intervention scores within groups 1 and 2 using repeated measures analysis.

\begin{tabular}{ccccccc} 
Groups & Balance scales & $\begin{array}{c}\text { Pre-intervention scores } \\
(\text { mean } \pm \text { SD) }\end{array}$ & $\begin{array}{c}\text { Post-intervention scores } \\
\text { (mean } \pm \text { SD) }\end{array}$ & F & $\begin{array}{c}\text { P } \\
\text { Partial Eta-squared } \\
\text { (effect sive) }\end{array}$ \\
Group 1 & TUGT & $13.45 \pm 2.04$ & $10.38 \pm 1.60$ & 172.75 & $0.001^{*}$ & 0.83 \\
Group 2 & BBS & $49.74 \pm 3.78$ & $54.69 \pm 1.13$ & 100.99 & $0.001^{*}$ & 0.74 \\
& TUGT & $13.51 \pm 2.09$ & $9.27 \pm 1.13$ & 304.26 & $0.001^{*}$ & 0.89 \\
\hline
\end{tabular}

Group 1, general balance and mobility exercise group; group 2, specific balance strategy training program group. TUGT, timed up and go test; BBS, Berg balance scale. *Significant at 0.05 level. 
back using the mirror provided to the patients during various tasks on different surfaces that might have led to the enhancement in balance. This idea is supported by the findings of Sihvonen et al., which suggest that balance training based on visual feedback improves balance control in frail elderly women living in residential care. ${ }^{23}$ The sit-to-stand-to-sit component being practiced helped in improving lower limb strength that might have led to improvement in post intervention scores. Improvement in the functional mobility component of balance may have resulted in improved timed up and go scores with specific balance-strategy training program while BBS scores improved as postural correction training activities were targeted in specific balance training strategy.

In the current study, subjects in both the groups: Specific balance-strategy training and the general balance and mobility exercise group benefited from the balance training interventions with a significant improvement in post-intervention balance scores on TUGT and BBS as compared to their pre-intervention scores. The general balance and mobility exercise program also showed significant improvements unlike previous studies of general exercise programs aimed at seniors which did not show significant results. ${ }^{24-26}$ The improvement shown in group 1 was less than that shown in group 2 as effect size for both the variables studied were more in group 2 . Group 1 showed a $22.8 \%$ improvement in TUGT scores and 9.95\% improvement in BBS post-intervention while group 2 showed a $31.38 \%$ and $10.76 \%$ improvement respectively post-intervention. A possible explanation could be that movement to the limits of stability was not an integral component nor were walking on different surfaces, turning and other rotational elements in group 1. Another advantage of the workstation application is the encouragement of self-efficacy in the participants who take control of their program by remembering what task to practice and how to increase the challenge at each station after consultation with the physiotherapist. General exercise group also focused on improving strength and flexibility, but focused more on strengthening of individual muscle group rather than through functional activities. Though sit-to stand component was included in both the groups, in specific balance strategy training group, alterations were made in the height of the chair and use of upper limb as assistance. As the patient progressed, the chair height was reduced and the assistance of the upper limb was minimized or removed. Also additional motor tasks such as balancing a cup with or without water and cognitive tasks such as counting backwards were added while the subjects performed sit to stand. In general balance group only sit-to stand was done without any additional task or alterations in chair height.

The result suggests that balance training program in community-dwelling elderly population above 65 years can improve balance even in short time duration. The results may have limited application in older frail adults with history of falls as the study sample was relatively healthy. The future interventions can focus on fallers or frail elderly population and can also include a longer protocol of balance training interventions with an appropriate follow up. The study was not registered in any of the clinical trial registry.

\section{Conclusions}

This study thus concludes that the subjects who participated in the specific balance-strategy training significantly improved their functional mobility, as shown on the TUGT, compared to the general training group.

\section{References}

1. Nelson RC, Amin M A. Falls in the elderly. Emerg Med Clin North Am 1990;8:309-24.

2. Masdeu JC, Sudarsky L,Wolfson L. Gait disorders of aging. Falls and therapeutic strategies. Philadelphia, PA: LippincottRaven; 1997.

3. Crilly RG, Willems DA, Trenholm KJ, et al. Effect of exercise on postural sway in the elderly. Gerontology 1989;35:137-43.

4. Hu M, Woollacott MH. Multisensory training of standing balance in older adults: I. Postural stability and one-leg stance balance. J Gerontol 1994;49:M52- 61.

5. Fiatarone MA, Marks EC, Ryan ND, et al. High-intensity strength training in nonagenarians. J Am Med Assoc 1990;263:3029-34.

6. Lichtenstein MJ, Shields SL, Shiavi RG, Burger C. Exercise and balance in aged women: a pilot controlled clinical trial. Arch Phys Med Rehabil 1989;70:138-43.

7. Silsupadol P, Siu Ka-C, Shumway-Cook A, Woollacott MH. Training of balance under single- and dual-task conditions in older adults with balance Impairment. Phys Ther 2006;86:269-81.

8. Wolf B, Feys H, De Weerdt, et al. Effect of a physical therapeutic intervention for balance problems in the elderly: a singleblind, randomized, controlled multicentre trial. Clin Rehabil 2001;15:624-36.

9. Ledin T, Kronhed AC, Möller C, et al. Effects of balance training in elderly evaluated by clinical tests and dynamic posturography. J Vest Res 1990-1991;1:129-38.

10. Nitz JC, Choy NL. The efficacy of a specific balance-strategy training programme for preventing falls among older people: a pilot randomized controlled trial. Age Ageing 2004;33:52-8.

11. Means KM, Rodell DE, 0'Sullivan PS. Balance, mobility, and falls among community dwelling elderly persons: effects of a rehabilitation exercise program. Am J Phys Med Rehabil 2005;84:238-50.

12. Ory MG, Schechtman KB, Miller JP, et al. Frailty and injuries in later life: the FICSIT trials. J Am Geriatr Soc 1993;41:283-96.

13. Province MA, Hadley EC, Hornbrook MC, et al. The effects of exercise on falls in elderly patients: a preplanned meta-analysis of the FICSIT trials. JAMA 1995;273:1341-47.

14. Howe TE, Rochester L, Neil F, et al. Exercise for improving balance in older people. Cochrane Database Syst Rev 2011;11:CD004963.

15. Podsiadlo D, Richardson S. The timed "up and go": a test of basic functional mobility for frail elderly persons. J Amer Ger Soc 1991;39:142-8.

16. Riddle DL, Stratford PW. Interpreting validity indexes for diagnostic tests: an illustration using the Berg balance test. Phys Ther 1999;79:939-48.

17. Shumway-Cook A, Baldwin M, Polissar NL, Gruber W. Predicting the probability for falls in community-dwelling older adults. Phys Ther 1997;77:812-19.

18. Lin MR, Hwang HF, $\mathrm{Hu} \mathrm{MH}$, et al. Psychometric comparisons of the timed up and go, one-leg stand, functional reach, and Tinetti balance measures in community-dwelling older people. J Am Geriatr Soc 2004;52:1343-8.

19. Berg KO, Wood-Dauphinee SL, Williams JI, Maki B. Measuring balance in the elderly: validation of an instrument. Can J Public Health 1992;83:S7-11.

20. Erdfelder E, Faul F, Buchner, A. GPOWER: A general power analysis program. Behav Res Meth Inst Comp 1996;28:1-11.

21. Shumway-Cook A, Gruber W, Baldwin M, Liao S. The effect of multidimensional exercises on balance, mobility, and fall risk in community dwelling older adults. Phys Ther 1999;77:46-57.

22. Botelho MF, Azevedo A. Manual reaction speed and manual dexterity in elderly people: A comparative study between elderly practitioners and non-practioners of physical activity. Sport Sci 2009;2:35-43.

23. Sihvonen SE, Sipila S, Era PA. Changes in postural balance in frail elderly women during a 4-week visual feedback training: a randomized controlled trial. Gerontology 2004;50:87-95.

24. McMurdo ME, Mole PA, Paterson CR. Controlled trial of weight bearing exercise in older women in relation to bone density and falls. BMJ 1997;314:569.

25. Means KM, Rodell DE, O'Sullivan PS, 
Cranford LA. 1996. Rehabilitation of elderly fallers: Pilot study of a low to moderate intensity exercise program. Arch Phys Med Rehabil 1996;77:1030-6.

26. Steinberg M, Cartwright C, Peel N,
Williams G. A sustainable programme to prevent falls and near falls in community dwelling older people: results of a randomized trial. J Epidemiol Community Health 2000;54:227-32. 